\title{
Contribution to the study of the Ce-Zr-Au system
}

\author{
A. Ait Chaou ${ }^{1}$, P. Lejay ${ }^{2}$ Ph. Galez ${ }^{1}$ and M. Lomello-Tafin ${ }^{1}$ \\ ${ }^{1}$ Laboratoire d'Instrumentation et des Matériaux d'Annecy, Université de Savoie, ESIA, \\ BP. 806, 74016 Annecy, France \\ ${ }^{2}$ Centre de Recherche sur les Très Basses Températures, CNRS, 25 Av. des Martyrs, \\ BP. 166, 38042 Grenoble, France \\ e-mail: marc.lomello@esia.univ-savoie.fr
}

\begin{abstract}
The equilibrium phase diagram of the $\mathrm{Ce}-\mathrm{Zr}-\mathrm{Au}$ system was studied by differential thermal analysis, X-ray diffraction and electron probe microanalysis along the isopletic section at 50 at. \% Au. Our main result concerns the discovery of a new ternary phase and a ternary invariant. The polymorphic transitions of the $\mathrm{ZrAu}$ phase, previously reported, was confirmed and we precised the melting and the polymorphic transition temperatures of the $\mathrm{CeAu}$ phase. A schematic representation of the isopletic section is given.
\end{abstract}

\section{INTRODUCTION}

The study of the isopletic section $\mathrm{ZrAu}-\mathrm{CeAu}$ (at 50 at. \% $\mathrm{Au}$ ) follows our previous works on the $\mathrm{Zr}$ $\mathrm{Au}$ system [1] and the determination of the crystal structures of the equiatomic compound, $\mathrm{ZrAu}$ [2]. No experimental investigation of phase equilibria in the Ce-Zr-Au ternary system has been published. Assuming similarity between the Ce-Zr and Ce-Ti systems, Moffatt has first drawn a hypothetical phase diagram without any intermediate phases, as later confirmed by Harris et al. [3]. No phase diagram has been clearly established for the Ce-Zr system. On the contrary, the $\mathrm{Zr}$ - $\mathrm{Au}$ and $\mathrm{Ce}-\mathrm{Au}$ binary systems are well known. The $\mathrm{Zr}-\mathrm{Au}$ system presents height intermetallic compounds $\left(\mathrm{Zr}_{3} \mathrm{Au}\right.$, $\left.\mathrm{Zr}_{2} \mathrm{Au}, \mathrm{Zr}_{3} \mathrm{Au}_{2}, \mathrm{ZrAu}, \mathrm{Zr}_{7} \mathrm{Au}_{10}, \mathrm{ZrAu}_{2}, \mathrm{ZrAu}_{3}, \mathrm{ZrAu}_{4}\right)$ and the solid-liquid equilibria has been determined by differential thermal analysis (DTA) in the whole composition range (fig. 1a). Recently, we have determined the three polymorphic forms of the congruent melting compound $\mathrm{ZrAu}$ by means of neutron powder diffraction [2]. At high temperature, ZrAu has a tetragonal structure $(P 4 / \mathrm{mmm}$, $a=4.835(2) \AA$ and $c=3.416(3) \AA)$ related to the $\mathrm{CsCl}$ structure, leading to a monoclinic structure $\left(P 2 / m, a=11.695(16) \AA, b=4.828(3) \AA, c=11.719(18) \AA, \quad E=107.090(17)^{\circ}\right)$ at $569^{\circ} \mathrm{C}$. A new transformation, which had not been detected in our previous work using DTA, leads to a triclinic structure $\left(P-1, a=11.537(8) \AA, b=4.841(1) \AA, c=11.507(7) \AA, D=87.42(1)^{\circ}, E=104.82(1)^{\circ}\right.$ and $\left.J=92.41(2)^{\circ}\right)$ around $380^{\circ} \mathrm{C}$. The assessed diagram for the Ce-Au system by Gschneidner $e$ al al (fig. $1 \mathrm{~b},[4])$ is primarily based on the work of Vogel et al. [5] with modifications based on the work of Mac Masters et al. concerning the Au-rich side [6]. Five intermetallic compounds have been identified: $\mathrm{Ce}_{2} \mathrm{Au}, \mathrm{CeAu}, \mathrm{CeAu}_{2}, \mathrm{Ce}_{14} \mathrm{Au}_{51}, \mathrm{CeAu}_{6}$. The congruent melting compound, $\mathrm{CeAu}$, presents two crystalline structures, orthorhombic with FeB-type (Pnma) below $480^{\circ} \mathrm{C}$ and orthorhombic with CrB-type $(\mathrm{Cmcm})$ at high temperature [6].

The purpose of this study is to establish the phase equilibria along the isopletic section between the two congruent melting compounds, $\mathrm{ZrAu}$ and $\mathrm{CeAu}$ (at 50 at. \% $\mathrm{Au}$ ). 


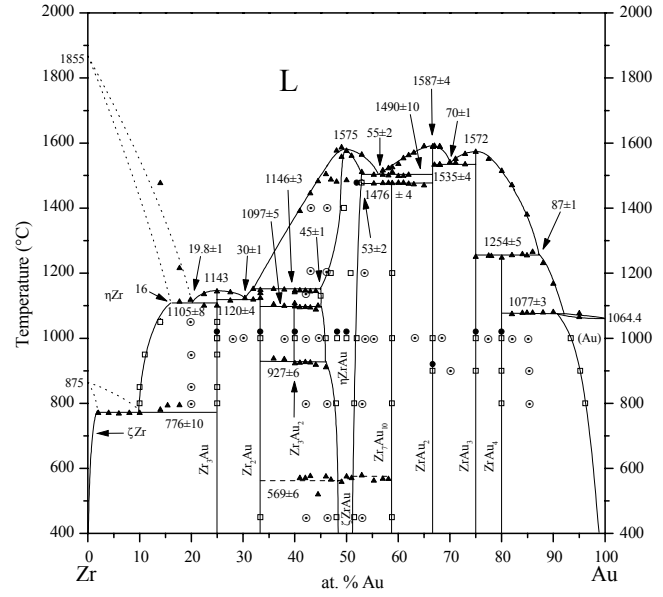

(a) From [1]

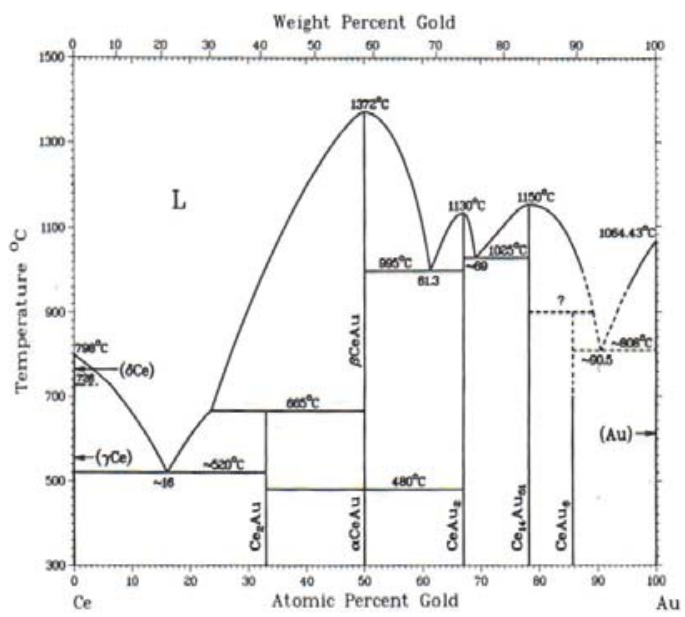

(b) From [5]

Figure 1. Equilibrium phase diagrams of Zr-Au system (a) and Ce-Au system (b).

\section{EXPERIMENTAL}

All samples were prepared by arc-melting under an Ar atmosphere, from zirconium and gold wires of $99.8 \%$ and $99.99 \%$ purity, respectively and from cerium metal pieces of $99.99 \%$ purity. Then, the ingots were annealed (for homogenisation) at $950^{\circ} \mathrm{C}$ under ultra-high vacuum $\left(2.10^{-10} \mathrm{mbar}\right)$.

Phase transitions were detected by DTA with heating and cooling rates of $10^{\circ} \mathrm{C} / \mathrm{min}$ between $25^{\circ} \mathrm{C}$ and $1600^{\circ} \mathrm{C}$. Alumina crucibles could be used up to $1000^{\circ} \mathrm{C}$ whereas, for higher temperatures, we preferred tungsten $(\mathrm{W})$ crucibles in order to avoid reaction with the sample.

The main difficulty of this work arose from the rapid oxidation of the alloys in air at room temperature. For this reason, X-ray diffraction (XRD) measurements were performed on polished samples, for which the kinetic for oxidation is expected to be slower than that for the powder. XRD collections were conducted using a diffractometer (Co KD) equipped with a position sensitive detector $5^{\circ}-120^{\circ}$ (INEL-CPS 120), allowing to limit the exposure time. For the cerium-rich samples, XRD were performed under He flow.

Electron probe microanalyses (EPMA) were performed on a Cameca SX50 device using the PAP correction software [7] and pure $\mathrm{Au}, \mathrm{Zr}_{2} \mathrm{Ni}_{7}$ and $\mathrm{CePO}_{4}$ as standards with the $\mathrm{Au}(\mathrm{LD})(\mathcal{O} 1.28206 \AA)$, $\operatorname{Zr}(\mathrm{LD})(\mathcal{O} 6.07415 \AA)$, and $\operatorname{Ce}(\mathrm{LD})(\mathcal{Q} 2.5615 \AA)$ radiations. The morphology of the sample was checked by optical and electron microscopies. 
Our main result concerns the discovery of a new ternary phase and a ternary invariant. From all equilibrium temperatures, we were able to propose a schematic representation of the isopletic section at 50 at. \% Au (fig. 2), including the liquidus surface.

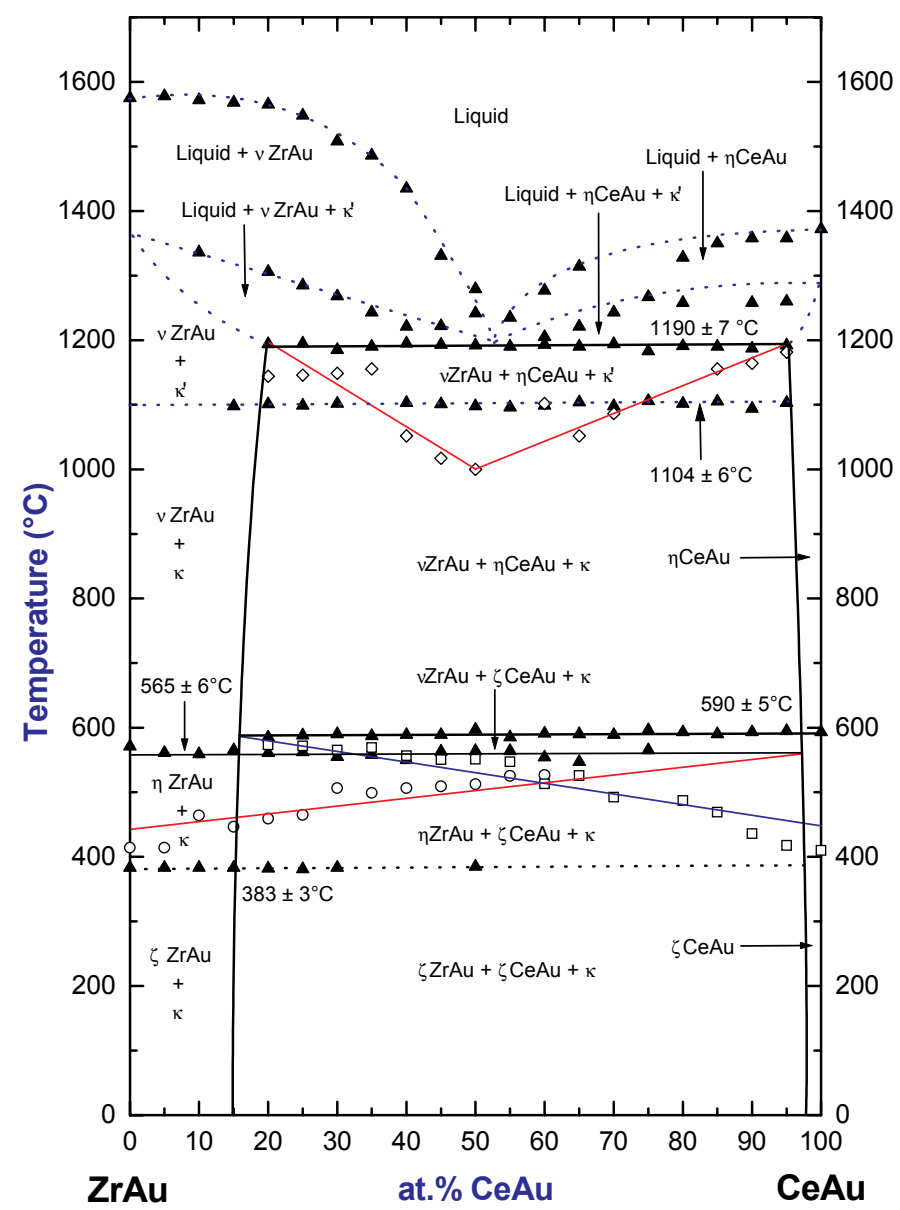

Figure 2. Schematic representation of the isopletic section at 50 at. \% Au ( $\mathbf{\Lambda}$ : heat effect detected by DTA ; $\diamond, \bigcirc, \square$ : Tammann analysis estimated from DTA).

\subsection{Isopletic section at 50 at. \% Au}

No solid solution of $\mathrm{Ce}$ in the $\mathrm{ZrAu}$ phase have been found from EPMA performed on the samples annealed at $950^{\circ} \mathrm{C}$. This result is coherent with regards to the respective atomic radii of $\mathrm{Zr}(1.60 \AA)$ and $\mathrm{Ce}(1.81 \AA)$, then the solubility of $\mathrm{Ce}$ in $\mathrm{ZrAu}$ is not expected. On the contrary, the solubility of $\mathrm{Zr}$ in $\mathrm{CeAu}$ was found to be 2 at. $\%$ at the annealing temperature $\left(950^{\circ} \mathrm{C}\right)$. The maximum solubility of $\mathrm{Zr}$ in $\mathrm{CeAu}$ at the temperature $\left(1190 \mathrm{r} 7^{\circ} \mathrm{C}\right)$ of the ternary eutectic do not exceed 3 at.\%. Indeed, endothermic effects, associated to the invariant plateau at $1190^{\circ} \mathrm{C}$, are still detected by DTA for the samples with a composition of $(\mathrm{ZrAu})_{0.05}(\mathrm{CeAu})_{0.95}$. 
DTA showed the presence of solid state reactions corresponding to the polymorphic transitions of the $\mathrm{ZrAu}$ and $\mathrm{CeAu}$ binary phases. The first one, detected at $383 \mathrm{r} 3^{\circ} \mathrm{C}$, is related to the triclinicmonoclinic transition of $\mathrm{ZrAu}$ observed around $400^{\circ} \mathrm{C}$ by neutron diffraction experiments [2]. It is interesting to note that this is most probably a second-order transition as no endothermic peak is detected by DTA. Indeed, the DTA curve presents a discontinuity as consequence of the change in heat capacity associated to the triclinic-monoclinic transition. The second at $565 \mathrm{r} 6^{\circ} \mathrm{C}$ is related to the monoclinic-tetragonal transition of $\mathrm{ZrAu}$ [1]. A polymorphic transition of the CeAu phase was first detected at $480^{\circ} \mathrm{C}$ (on cooling) by Mc Masters et al. [6]. We found 590r $5^{\circ} \mathrm{C}$ by DTA on heating and the temperature measured on cooling was found to be $460^{\circ} \mathrm{C}$, in agreement with the work of $\mathrm{Mc}$ Masters et al.
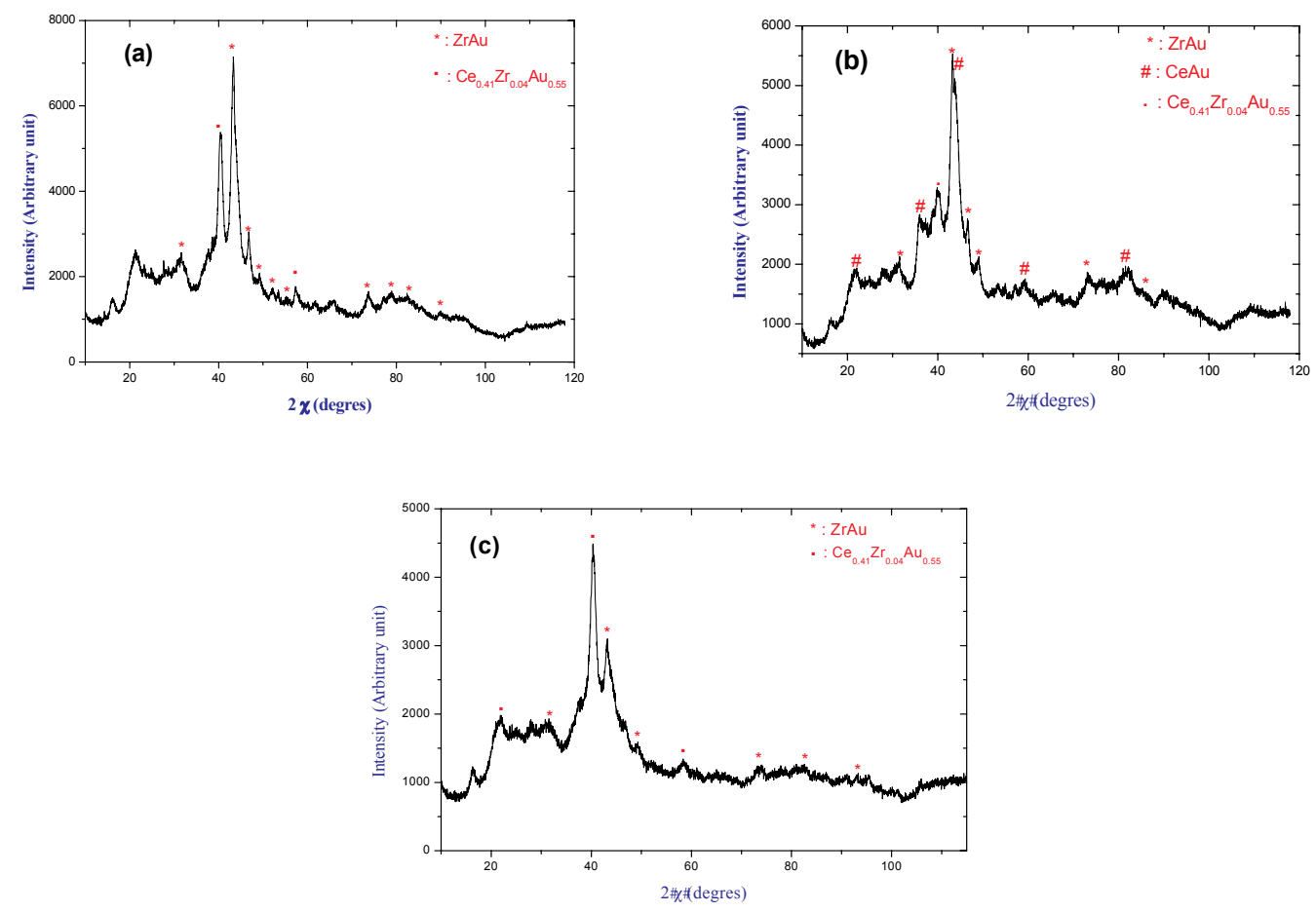

Figure 3. XRD patterns of $\mathrm{Ce}(12,5 \%) \mathrm{Zr}(37,5 \%) \mathrm{Au}(50 \%)$ annealed for 13 days at $1000^{\circ} \mathrm{C}$ (a), as cast arc-melted $\mathrm{Ce}(25 \%) \operatorname{Zr}(25 \%) \mathrm{Au}(50 \%)$ (b) and as cast arc-melted $\mathrm{Ce}(24 \%) \operatorname{Zr}(24 \%) \mathrm{Au}(52 \%)$ (c).

At higher temperatures, DTA measurements revealed the presence of two invariant plateau at $1104 \mathrm{r} 6^{\circ} \mathrm{C}$ and $1190 \mathrm{r} 7^{\circ} \mathrm{C}$. The first one, represented as dotted lines in Figure 2 , is probably due to a polymorphic transition of a new ternary phase (composition close to $\mathrm{Ce}_{41} \mathrm{Zr}_{4} \mathrm{Au}_{55}$ ) with regards to DTA experiments performed on several ternary samples. We observed that the peak area associated to this transition is clearly related to the amount of the new phase $(\mathrm{H}$. The thermodynamic properties of the later are still under investigations. The invariant reaction, occurring at $1190^{\circ} \mathrm{C}$, unambiguously implies $\mathrm{ZrAu}, \mathrm{CeAu}$ and $\mathrm{H}$ Indeed, XRD of the $\mathrm{Ce}(25 \%) \mathrm{Zr}(25 \%) \mathrm{Au}(50 \%)$ sample annealed under ultra-high vacuum at $950^{\circ} \mathrm{C}$ (fig. $3 \mathrm{~b}$ ) revealed an equilibrium between $\mathrm{Zr}_{48} \mathrm{Au}_{52}, \mathrm{Ce}_{48} \mathrm{Zr}_{2} \mathrm{Au}_{50}$ and $\mathrm{H}$ Figure 4 shows a schematic representation of the phase equilibria counted in the proximity of the $\mathrm{ZrAu}-\mathrm{CeAu}$ section at $950^{\circ} \mathrm{C}$. From the liquidus surface (fig.2), we suggest that the invariant may be a ternary eutectic. However, more work has to be done in order to precise the nature of this invariant which depends on the formation type of $\mathrm{H}$ still unknown. Details in the ternary phase field will be published elsewhere. 


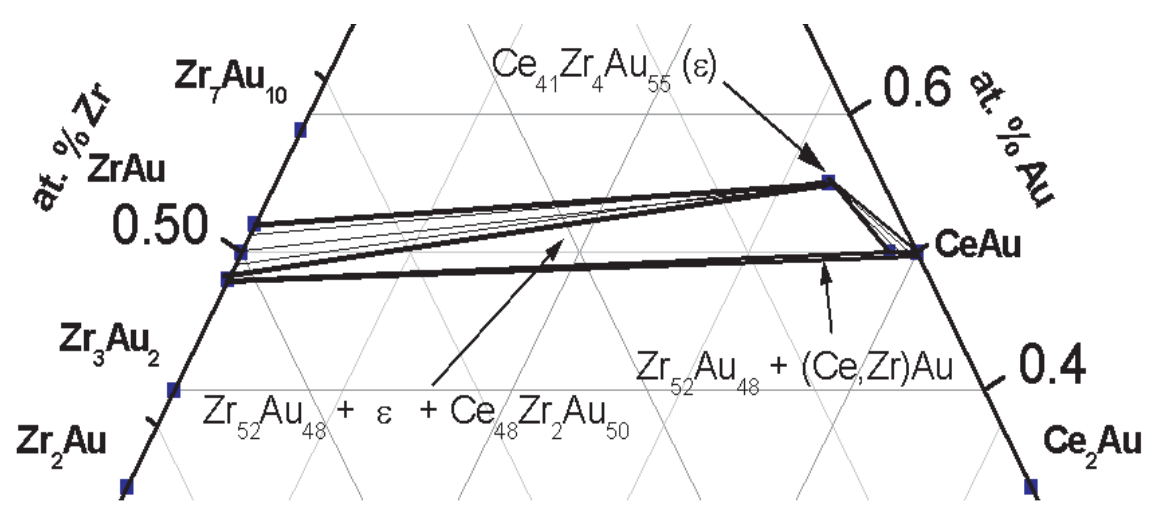

Figure 4. Equilibria at $950^{\circ} \mathrm{C}$ in the proximity of the $\mathrm{ZrAu}-\mathrm{CeAu}$ section.

In spite of the determination of the liquidus curves thanks to the use of $\mathrm{W}$ crucibles, the phase equilibria implying the liquid phase are not yet clearly established and appear as dotted lines in the isopletic section. Heat treatments performed in a high-frequency furnace followed by argon jet quenching are still under work in the laboratory, in order to precise the phase equilibria at high temperature.

\subsection{The new ternary phase $\mathrm{H}$}

The presence of Hhas been observed in samples annealed under ultra-high vacuum $\left(2.10^{-10} \mathrm{mbar}\right)$ at $950^{\circ} \mathrm{C}$ during 15 days. The composition of $\mathrm{H}$ was estimated from EPMA and we obtained $\mathrm{Ce}_{41} \mathrm{Zr}_{4} \mathrm{Au}_{55}$. In order to characterise the structural and thermodynamic properties of the new phase, we have prepared several samples with a composition close to that measured by EPMA. Figure 5 shows a optical micrograph of as cast arc-melted $\mathrm{Ce}_{39} \mathrm{Zr}_{4} \mathrm{Au}_{57}$, which reveals the primary crystallisation of $\mathrm{H}$ (grey). The XRD pattern of as cast $\mathrm{Ce}_{39} \mathrm{Zr}_{4} \mathrm{Au}_{57}$ (fig. 6) reveals a characteristic diffraction peak $\left(2 T=40^{\circ}\right)$ which can not be attributed to $\mathrm{ZrAu}$ and $\mathrm{CeAu}$ nor to the neighbouring binary phases. The determination of the crystal structure of His still under work.
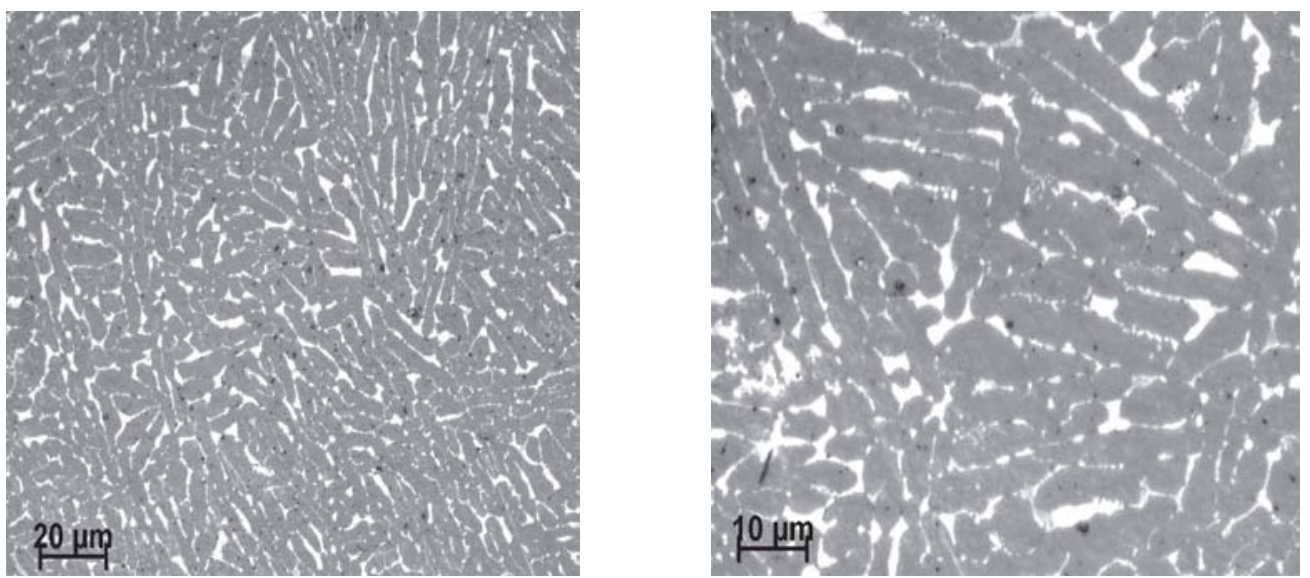

Figure 5. Micrographs of as cast arc-melted $\mathrm{Ce}(39 \%) \mathrm{Zr}(4 \%) \mathrm{Au}(57 \%)$ sample. 


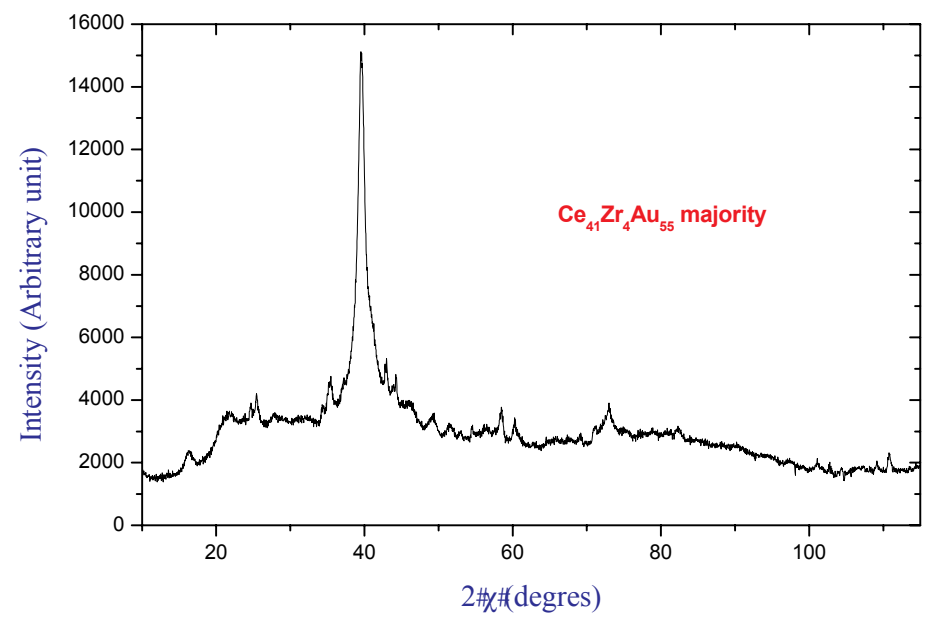

Figure 6. XRD pattern of as cast arc-melted $\mathrm{Ce}(39 \%) \mathrm{Zr}(04 \%) \mathrm{Au}(57 \%)$.

\section{Acknowledgements}

We gratefully thank Dr. Florence Robaut (Consortium des Moyens Technologiques Communs, Institut National Polytechnique de Grenoble) for her help during the electron probe microanalysis. The financial support by the Région Rhône-Alpes (program Avenir and an accompanying Ph.D. grant) is greatly acknowledged.

\section{References}

[1] M. Lomello-Tafin, P. Galez, J.C. Gachon, P. Feschotte, J.L. Jorda, J. All. Comp. 257 (1997) 215

[2] J. M. Moreau, M. Isa, A. Ait Chaou, M. Lomello-Tafin, J. Jourdan, Ph. Galez, J.C. Valmalette, J.L. Soubeyroux, J. All. Comp. 373 (2004) 16

[3] I.R. Harris and G.V. Raynor, J. Less Com. Met. 6 (1964) 70

[4] K.A. Gschneidner et al., Binary Alloys Phase Diagrams, (2d edition) Vol. 1 (1990) 352

[5] L. Rolla, A. Jandelli, G. Canneri und R. Vogel, Z. Metallkd., 29 (1943) 35

[6] O.D. McMasters, K.A. Gschneidner, Jr., G. Bruzzone, A. Palenzona, J. Less-Com. Met., 25 (1971) 135

[7] J.L. Pouchou and F. Pichoir, La recherche Aérospatiale, 3 (1984) 167 